\title{
A PROFISSIONALIZAÇÃO DO PROFESSOR: CONDIÇÃO NECESSÁRIA PARA UMA PRÁTICA RESPEITÁVEL
}

\author{
Marcos Gustavo Richter \\ mrichter@cal.ufsm.br \\ Jaci Rene Costa Garcia \\ garciaadv@terra.com.br
}

\section{RESUMO}

Este artigo tem por objetivo debater o problema da profissionalização do professor, examinando alguns aspectos teóricos e empíricos e traçando um comparativo com profissões afins já emancipadas. Partimos de uma pesquisa de textos que demonstram a importância da construção identitária para justificar teoricamente a tese da profissionalização do professor para, num segundo momento, refletirmos sobre as possibilidades e o grau de necessidade da construção de uma identidade profissional e da regulamentação de um território que delimite o universo de atuação desse profissional.

\section{CONSIDERAÇÕES INICIAIS}

A reflexão proposta pretende aprofundar uma preocupação teórica imbricada e implicada com a prática da docência no Brasil, com a construção de território e, principalmente, com a demonstração de um problema que se nos apresenta da maior relevância, ou seja, uma pergunta que nos incomoda e que está na origem das questões que envolvem o processo educacional no Brasil: a profissionalização do professor seria condição necessária para uma prática respeitável?

O problema da pesquisa exige que se demonstre a relevância para, num momento posterior, sejam examinadas algumas pretensas soluções, quando será pertinente investigarmos algumas profissões regulamentadas e a contribuição social que se dá a partir da constituição sistêmica da profissão, da delimitação territorial, da possibilidade de produção de um discurso endógeno e da identificação, esta que se constrói a partir de uma área definida, de um olhar que contempla a "si mesmo" e de uma profissão que passa a existir e ser respeitada no campo da alteridade.

Trataremos, então, da profissionalização do professor como princípio de mudanças estruturais no próprio Estado, dado que a sua emancipação, num processo de interação dialética com o social, tanto é importante para o profissional que passará a ocupar um espaço sistemicamente delimitado como, ao mesmo tempo, adquire 
um caráter de essencialidade para a sociedade que terá definida as competências de um profissional que intervém no processo de formação dessa sociedade.

Em artigo anterior, refletimos sobre as possibilidades e o grau de necessidade da construção de uma regulamentação que delimitasse o universo de atuação desse profissional e, considerando o cenário legislativo, demonstramos a possibilidade jurídica dessa construção. No presente trabalho, centramos a nossa preocupação em demonstrar a necessidade fática dessa profissionalização, para o professor e para a sociedade, a partir de textos que nos permitem realizar tais inferências. Buscamos, em síntese, o esclarecimento de que discutir educação no Brasil passa pela instância do papel de um novo professor: um profissional emancipado.

\section{A DEMONSTRAÇÃO DIALÉTICA DE UMA PRÁTICA NÃO PROFISSIONAL: O PROFESSOR COMO COISA CARENTE-DE-SI}

Desde Hegel temos uma clara percepção da ausência de identidade proposta na relação entre o senhor e o escravo, quando o filósofo diz que "o senhor considera o escravo não como pessoa, mas como coisa carente-de-si, e o escravo não conta como um Eu, mas o senhor é o seu Eu" (Ciência da Lógica, § 163, p. 298). Para Hegel o princípio da personalidade é a universalidade e, ainda, encontramos no pensador que o universal é o idêntico consigo mesmo, contendo as determinações e diferenciações da particularidade e a significação de ser sujeito dada pela categoria da singularidade.

A clareza da visão filosófica permite uma transposição da filosofia hegeliana para a nossa análise do professor e nos permite inferir que este não produz um discurso com "tendências à universalização", que não estabelece diferenças (limites constitutivos) e não permite a singularização, encontrando-nos diante de uma "coisa carente-de-si" na conceituação hegeliana.

$\mathrm{Na}$ literatura de Homi Bhabha (O local da cultura) surge a dialética do colonizador e do colonizado que nos permite algumas transposições entre essas categorias, especialmente a do colonizado (cujo lugar sócio-cultural é constituído exogenamente), expressa na angústia de um professor que busca (ou deveria buscar) a sua construção identitária. A partir de um exercício dialético, que exclui um modelo de conteúdo essencialmente idealista, Bhabha traz importantes contribuições para uma compreensão de um mundo estereotipado e fetichizado, mundo construído por um discurso do colonizador que é internalizado pelo colonizado. Parece-nos que o professor do nosso problema de pesquisa se apresenta como um professorcolonizado, aquele que se deixa fisgar pelo campo semântico do colonizador e que, urgentemente, precisa criar uma exterioridade intradiscursiva para que, antes de discutir aspectos educacionais relevantes, seja capaz de eleger uma pauta e, como ponto inaugural, discutir o seu próprio processo emancipatório. 
Cirurgicamente pescamos algo que nos mostra inclusão e exclusão no discurso de Bhabha quando cita Fanon e explora um pouco o excerto transcrito (Bhabha, p. 76):

\begin{abstract}
'Você é um médico, um escritor, um estudante, você é diferente, você é um de nós.' É precisamente no uso ambivalente de 'diferente' - ser diferente daqueles que são diferentes faz de você o mesmo - que o Inconsciente fala da forma da alteridade, a sombra amarrada do adiamento e do deslocamento. Não é o Eu colonialista nem o outro colonizado, mas a perturbadora distância entre os dois que constitui a figura da alteridade colonial.
\end{abstract}

Na sociedade global e na brasileira, ambas como um grande sistema de sistemas, pode-se dizer que o artifício criado pelos Ordenamentos e pela aceitação histórica do poder dado às normas jurídicas, demonstra que a profissão regulamentada adquire um status superior aquela não regulada, prestando-se o sistema Direito a construir outros sistemas (com a correspondente projeção de suas imagens) e proporcionando visibilidade ao que antes empiricamente "existia e não era visto".

Parece-nos que o professor sofre dessa "invisibilidade", em razão da não regulamentação da profissão e, por inspiração de Bhabha, diríamos que profissões regulamentadas guardam uma perturbadora distância do professor, sendo que essa assimetria dada pelo afastamento é mais um sinal da relação colonial existente (a regulamentação como ato jurídico é "uma diferença que faz diferença", para empregarmos a expressão consagrada de Gregory Bateson).

\title{
3. A AUSÊNCIA DE PROFISSIONALIZACCÃO DE UM FORMADOR DE PRO- FISSIONAIS: A PERCEPÇÃO DO "PARADOXO DO PROFESSOR" NA TEORIA DOS SISTEMAS
}

Percebemos que há uma grande dificuldade tanto do colonizado quanto do escravo de escaparem de uma situação de inferioridade, uma vez que internalizam discursos que não contribuem - e mais - inibem o processo emancipatório. Como exemplo de interiorização de discurso exógeno, temos a aceitação pacífica e adjetivação externa de "heróica" aos trabalhos pedagógicos realizados em condições precárias, a aceitação das pseudo-ajudas como os "amigos da escola", a reprodução acrítica dos discursos da classe política dominante. Todos esses são fatores que contribuem para a mantença da condição de colonizado e/ou escravo.

Essa capacidade de os dominados incorporarem o discurso dos dominadores aparece em Elias' (Os Estabelecidos e os Outsiders) quando relata um estudo realizado em uma pequena comunidade, onde a diferença entre seus moradores consistia apenas no tempo de residência, constatando uma recorrência nas relações que se estabelecem entre os grupos, a partir da inferência de que praticamente em todas as sociedades os grupos estabelecidos há mais tempo, com história de vida em comum, estigmatizam outros grupos como sendo de status inferior e de menor valor. Discurso desse nível, quando internalizado pelos outsiders, revela que a he- 
rança social exercerá influência importante no modo de vida do grupo classificado como inferior.

Processo semelhante ocorre com o professor em relação às demais profissões regulamentadas, parecendo-nos elucidativa a extrapolação da obra de Elias para a configuração da tragédia vivida por esse profissional sem território. Haveremos, por uma questão de resgate histórico, demonstrar que há necessidade de outorgar personalidade jurídica ao professor a partir da normatização das suas atividades, forte na força simbólica exercida pelo universo do jurídico e pelo poder de repercutir essa força ao regulamentar uma área.

Pross (1980), ao refletir sobre a formação da linguagem (e podemos pensar como linguagem a forma de manifestação "normativa" do sistema direito), encontra como antecedentes categorias que ordenam a formação de simbolismos, apontando as como experiências primárias relevantes do ser humano: claro-escuro, dentrofora, acima-abaixo. Podemos dizer que um pensamento em ordem é o que está em coordenação com essas experiências primárias, sendo que o Direito (enquanto Ordenamento) está sistematicamente organizado e possui - enquanto Sistema - a capacidade de eleger o "acima" a partir de um código binário interesse/nãointeresse, sendo lícito concluir que, por exemplo, uma profissão em que há interesse e passa a ser "regulamentada" possui "mais valia" do que uma "não regulamentada", sendo que tal inferência nos parece possível pela força simbólica do Direito nas sociedades atuais.

Por força da utilização da expressão "sistemas" ao longo da pesquisa, é forçoso registrar alguns fragmentos de um trabalho extenso de Bertalanffy contribuindo para uma percepção sistêmica das ciências (anos 50/60 do séc. XX) e, ao tratar dos rumos da Teoria dos Sistemas, relacionar com diversas teorias existentes, apontando que a 'teoria dos jogos (von Neumann e Morgenstern, 1947) é um enfoque diferente mas pode ser classificado entre as ciências dos sistemas" (Bertalanffy, p. 42), justificando a sua assertiva na racionalidade do jogo onde os jogadores buscam um máximo de ganho e um mínimo de perda, caracterizando uma tensão e uma polarização no antagonismo das forças em atuação.

Nesse sentido, constatamos que o professor está inserido num jogo de forças em que a possibilidade de mudança de cenário passa por estar inserida a sua reivindicação emancipatória numa agenda política, esperando que o poder político (e seu entorno) crie condições para a construção normativa desse profissional emergente. Nesse rumo à emancipação, caberia recordarmos que a livre escolha dos indivíduos poderia ser descrita por formulações da teoria dos jogos e da decisão (Bertalanffy, p. 160); porém percebemos um grande problema (e que serve de alerta às ações que podem ser implementadas) em razão de que, quando se trata de expectativas sobre sujeitos (ou do que é lícito esperar do outro em termos de ação racional), vale a advertência sempre atual de Oxenstierna, chanceler da Suécia durante a Guerra dos Trinta Anos, nos termos: Nescis, mi fili, quantilla ratione mundus regatur, "você não sabe, meu filho, com quanta falta de razão o mundo é governado". 
Com essa advertência, todas as ações a serem tomadas devem incluir o político e devem ser cuidadosamente sopesadas, uma vez que o professor tem sido (paradoxal e espantosamente) o "não profissional" formador de todas as profissões. A necessidade de profissionalização de quem detém a tarefa de formar futuros profissionais é uma obviedade histórica, um paradoxo não resolvido, mas que necessita de um extremo cuidado no trato pelos interesses que podem e devem estar em jogo.

Cumpre registrarmos na contemporaneidade Luhmann com sua renovação da teoria geral dos sistemas (criada nos anos 50 por Bertallanfy) através da introdução, na Sociologia, do conceito de autopoiese formulado pelos biólogos chilenos Humberto Maturana e Francisco Varela, na obra "De Máquinas y Seres Vivos" (1973). Visando a superar a tradicional antinomia entre os mecanicistas e os vitalistas, os biólogos chilenos apontam uma terceira via de defesa de uma organização autoreferencial dos seres vivos, onde a respectiva ordem interna é gerada a partir da interação dos seus próprios elementos e é auto-reprodutiva.

O sistema autopoiético pode se definido como aquele dotado de organização onde há a (re)produção dos elementos de que se compõe o sistema e que geram sua organização pela relação recursiva entre eles. Esse sistema possui autonomia porque o que nele se passa não é determinado por nenhum componente externo (do ambiente) mas sim por sua própria organização, isto é, pelo relacionamento entre seus elementos (estruturas). Essa autonomia do sistema tem por condição sua clausura (fechamento), quer dizer, a circunstância de ser "fechado", do ponto de vista de sua organização, não havendo entradas e saídas para o ambiente ${ }^{i i}$, pois os elementos interagem e através dele são possíveis as conexões com as extremidades do sistema, percebendo-se o que pertence e o que não pertence ao sistema (Guerra Filho, 1999, p. 58).

A determinação dada pela profissionalização de uma categoria permite que se fale em sistema autopoiético, com autonomia funcional gerada pelos Conselhos e por estruturas conectas e relacionadas endogenamente. O professor necessita da sistematização de suas atividades, da regulamentação que atribui imagem (e extremidades), para que se fale legitimamente em pertencimento, para que se pense que o professor é diferente de uma outra classe profissional mas também é uma classe profissional. Num mundo complexo, o processo identitário de classes pressupõe uma organização sistêmica onde o Direito (e a sua produção simbólica) possui um papel decisivo.

\section{O PROFESSOR COMO PORTADOR DE SÍMBOLOS DO ESTADO: O PODER INSTITUÍDO E A COOPTAÇÃO DO PROFESSOR}

Diz Bourdieu que "a sociologia não poderá escapar de todas as formas de dominação que a lingüística e seus conceitos exercem sobre as ciências sociais" (Bourdieu, p. 23), sublinhando que - embora legítimo o trato das relações sociais 
como interações simbólicas - há que se cuidar da questão relativa ao "poder simbólico" e, nesse sentido, a preocupação do autor com um ajustamento que implica numa visão que valoriza o aspecto sociológico da linguagem. Tratando da produção a partir da língua como "produto lingüístico", considera o funcionamento interno do sistema (gramática), a partir de distinções dadas no interior da estrutura, apenas como parte da definição de sentido, entendendo que a parte maior das determinações se transferem de fora para o interior do discurso.

A capacidade de penetração dos símbolos pode ser sintetizada: primeiro, na confiança original de que o símbolo é "algo" (algo que se deve considerar como meio para se chegar a outra coisa) e não uma ilusão do intérprete; segundo, essa relação é uma forma capaz de reafirmar o intérprete numa realidade. Uma ordem perde credibilidade quando não mais funciona o sistema de sanções pertencentes ao sistema simbólico, que pode ocorrer e indica a crise do instituído que esbarra na resistência de um povo (O professor atua na consciência de um povo e sempre há um perigo para quem exerce o poder na emancipação de portadores de símbolos).

Em Pross (p. 119), encontramos: "não há nenhuma 'causa grande' sem gente que se ponha a seu 'serviço'." Com exemplo, demonstra que o sistema simbólico e o sistema sancionador dependem não só do vértice, mas também (e muito) da base da pirâmide, ou seja, dos sujeitos que atuam como portadores de símbolos. O professor, na condição de não-emancipado, atua como um portador de símbolos da classe política dominante. Vale dizer, então, que a luta pela emancipação é uma tarefa hercúlea e que necessita de uma conscientização de toda uma categoria, do meio social no qual se insere e, principalmente, de um começo, não somente nas bases como também no âmbito das ações centralizadas (jurídicas).

\section{UM PARADIGMA: A REGULAMENTAÇÃO DA PROFISSÃO DE EDUCAÇÃO FÍSICA}

A Lei 9.696 , de $1^{\circ}$ de setembro de 1998, dispõe sobre a regulamentação da profissão de Educação Física, cria a profissão (art. $1^{\circ}$ ), atribui identidade (art. $2^{\circ}$ ), delimita o território de competência (art. $3^{\circ}$ ) cria os respectivos Conselho Federal e Conselho Regionais de Educação Física (art. 4ํe e 5), gerando um micro-sistema onde o novo profissional será capaz de se organizar e autoproduzir.

Transcreve-se a Lei 9.696/98:

"Art. 1ํ O exercício das atividades de Educação Física e a designação de Profissional de Educação Física é prerrogativa dos profissionais regularmente registrados nos Conselhos Regionais de Educação Física.

Art. $2^{\circ}$ Apenas serão inscritos nos quadros dos Conselhos Regionais de Educação Física os seguintes profissionais:

I - os possuidores de diploma obtido em curso de Educação Física, oficialmente autorizado ou reconhecido; 
Il - os possuidores de diploma em Educação Física expedido por instituição de ensino superior estrangeira, revalidado na forma da legislação em vigor;

III - os que, até a data do início da vigência desta lei, tenham comprovadamente exercido atividades próprias dos Profissionais de Educação Física, nos termos a serem estabelecidos pelo Conselho Federal de Educação Física.

Art. 3 Compete ao Profissional de Educação Física coordenar, planejar, programar, supervisionar, dinamizar, dirigir, organizar, avaliar e executar trabalhos, programas, planos e projetos, bem como prestar serviços de auditoria, consultoria e assessoria, realizar treinamentos especializados, participar de equipes multidisciplinares e interdisciplinares e elaborar informes técnicos, científicos e pedagógicos, todos nas áreas de atividades físicas e do desporto.

Art. 4ํ Ficam criados o Conselho Federal e os Conselhos Regionais de Educação Física.

Art. $5^{\circ}$ Os primeiros membros efetivos e suplentes do Conselho Federal de Educação Física serão eleitos para um mandato tampão de dois anos, em reunião das associações representativas de Profissionais de Educação Física, criadas nos termos da Constituição Federal, com personalidade jurídica própria, e das instituições superiores de ensino de Educação Física, oficialmente autorizadas ou reconhecidas, que serão convocadas pela Federação Brasileira das Associações dos Profissionais de Educação Física - FBAPEF, no prazo de até 90 (noventa) dias após a promulgação desta lei.

Art. 6ํㅗ Esta lei entra em vigor na data de sua publicação." (Os grifos são nossos).

A criação de entidades representativas dos profissionais serve, em sentido amplo, para fiscalizar o exercício da profissão e, via reflexa, é um fator que agrega respeito e contribui para delimitar o território de atuação, dividindo áreas de atuação interdisciplinares com outros profissionais - como no caso examinado, em que podem surgir conflitos entre o Profissional de Educação Física e o Fisioterapeuta, por exemplo.

Por certo a emancipação profissional não elide aprioristicamente todos os problemas; porém, aclara essas questões e permite que sejam resolvidas a partir de um embate em igualdade de forças, como na hipótese de um conflito no exercício de atividades entre profissionais que possuem uma zona de penumbra em algumas de suas atividades (materializando o exemplo proposto, poder-se-ia levantar uma questão: compete a ambos a reeducação postural?). Situações que surgem no interior de sistemas juridicamente construídos e, em assim sendo, a voz que ressoa parte de Conselhos que possuem personalidade jurídica própria (art. 5ํํㄹ da Lei 9.696/98), dando-se um jogo que, pelo respeito às forças sistemicamente moduladas, invariavelmente são resolvidos pela negociação (equivalência das forças). No caso do professor, dada a inexistência da regulamentação da profissão, a correlação de forças é sempre desigual, independentemente de seu hipotético opositor. Há nessa função social uma fraqueza e erraticidade imanentes que confrangem 
sobremaneira quem se detenha a refletir seriamente sobre as condições de acesso e exercício da mesma.

\section{CONSIDERAÇÕES PROVISORIAMENTE FINAIS}

O professor, dentre os profissionais ligados à formação e ao desenvolvimento humano, exerce uma semiprofissão na medida em que seu campo de atuação caracteriza-se pela ambivalência. Ou seja, embora seja entendido como participante ativo da organização do empreendimento educativo - inclusive como formador das demais profissões - ocupa um lugar social passivizado, que o constitui e interpela como objeto de prescrição de normas. As principais variáveis de sua esfera de ação, a saber, a identidade, as relações de trabalho entre profissional e leigo e entre pares e a delimitação de competências, são assenhoreadas por uma instância decisória exterior ao próprio grupo (exogenia), caracterizando-o como nãoemancipado.

Contrasta com este quadro a situação das profissões emancipadas, como por exemplo, a do profissional de Educação Física. Hoje, precisamente por sua condição de endogenia recém-adquirida, detém um estatuto peculiar entre os profissionais da educação, na medida em que goza de autonomia diante da clientela e das organizações. Com efeito, em um campo de atuação autônomo, a relação do sistema de atividade com o seu entorno - mais precisamente, a relação profissionalleigo - consiste em um mais-saber e mais-poder a priori: competência acompanhada de discurso eficaz quanto ao efeito de verdade. A relação com outros profissionais (relação intersistêmica) é complexa, pode implicar diferentes e múltiplas relações de força, mas preserva um "território" intocável de competências e ingerências, principalmente em contextos típicos da profissão.

Já o professor, tutelado pelo Estado, não-emancipado, nominalmente restringe sua suposta "autonomia" à sala de aula, cabendo-lhe ser mero co-participante da micropolítica do estabelecimento de ensino em que atua, ao lado de alunos e pais. Somente o ensino superior abre um espaço apreciável de autonomia, embora limitada, para esta classe basicamente heterônoma. Espaço este, mesmo assim, restrito às universidades públicas: Mello (1999) demonstra, num estudo de caso envolvendo uma universidade privada, a relação entre a política de "qualidade total" da instituição e as estratégias discursivas de cooptação do quadro docente, mantendo subjacente uma polarização exógena administrador-professor.

Esta oposição, autonomia-heteronomia, aproxima-se da sua correlata endogeniaexogenia, sem recobri-la estritamente. Isto porque, a nosso ver, autonomia esgota-se no poder decisório e nos mecanismos de legitimação que os acompanham, enquanto que endogenia é um conceito mais amplo: engloba este aspecto e outros dois: o efeito de verdade, associado ao lugar discursivo de onde emanam efeitos de sentido destinados a "dar fé", e o efeito de prestígio, a (auto-)constituição de uma imagem com ênfase no valor social a ela agregado - valor do profissional, de seu trabalho, de seu conhecimento, de sua formação. A endogenia, portan- 
to, se desdobra em três efeitos discursivos: efeito de prestígio, efeito de legitimidade e efeito de verdade.

\section{BIBLIOGRAFIA}

BERTALANFFY, Ludwig von. Teoria Geral dos Sistemas. Tradução de Francisco M. Guimarães. Rio de janeiro: Petrópolis, Vozes, $2^{\underline{a}}$ ed., 1975.

BHABHA, Homi K. O local da Cultura. Belo Horizonte: Ed. UFMG, 1998.

BOURDIEU, Pierre. A Economia das Trocas Lingüísticas: O que Falar Quer Dizer. São Paulo: EDUSP, 1996.

ELIAS, Norbert. Os estabelecidos e os outsiders: sociologia das relações de poder a partir de uma pequena comunidade. Rio de Janeiro: Jorge Zahar Ed., 2000.

GUERRA FILHO, Willis Santiago. Autopoiese do direito na sociedade pós moderna: introdução a uma teoria social sistêmica. Porto Alegre : Livraria do Advogado, 1997.

HEGEL, Georg Wilhelm Friedrich. Enciclopédia das Ciências Filosóficas em Compêndio, vol. 1, A Ciência da Lógica. São Paulo: Loyola, 1995.

LUHMANN, Niklas. Sociologia do direito. Volumes I e II. Rio de Janeiro : Tempo Brasileiro , 1985

MELLO, Elizabeth E. Práticas Discursivas na Construção de uma Imagem Institucional. São Paulo: PUCSP, 1999, Dissertação de Mestrado.

PROSS, Harry. Estructura simbólica del poder. Barcelona: Editorial Gustavo Gili S. A., 1980

\footnotetext{
' Em resenha elaborada por Cláudio Perrone-Moisés, professor do departamento de Direito Internacional da Faculdade de Direito da USP, diz o emérito Professor que "embora Elias raramente faça referências a outros autores, na sua teoria das relações de poder pode se reconhecer um diálogo com Hegel (a questão do reconhecimento na dialética do senhor e do escravo), Simmel (os conflitos como vínculos de tensão e desigualdade sociologicamente positivas), Weber (o problema da legitimidade nas formas de dominação), Durkheim (a noção de coesão e a idéia de que as rela-
} 
ções sociais podem ser de intensidade variável), Freud (a relação entre identidades individuais e coletivas) e Bateson (as noções de double-bind e de cismogênese)"

"A esse respeito, cabe assinalar que o "fechamento" diz respeito estritamente à organização do sistema e tudo que diga respeito a ela. Por exemplo, falando empiricamente do espaço sistêmico, matérias-primas ingressam e produtos de descarte egressam constantemente, mas ressalvando que as primeiras se constituem:

a) Ou de objetos que, embora descritivamente se assemelhem a constituintes internos, não exercem as funções destes últimos fora do sistema ou no momento do ingresso;

b) Ou de precursores dos objetos ou partes funcionais, tendo que passar por algum processo de construção ou modificação estrutural para que se convertam naqueles. 